\title{
Real-time monitoring efficiency and toxicity of chemotherapy in patients with advanced lung cancer
}

Hong Wang ${ }^{1,2+}$, Bingfeng Zhang ${ }^{1,2+}$, Dan Chen ${ }^{1,2+}$, Wenying Xia ${ }^{1,2}$, Jiexin Zhang ${ }^{1,2}$, Fang Wang ${ }^{1,2}$, Jian Xu $u^{1,2}$, Yan Zhang ${ }^{1,2}$, Meijuan Zhang ${ }^{1,2}$, Lixia Zhang ${ }^{1,2}$, Yachun Lu ${ }^{1,2}$, Yan Geng ${ }^{1,2}$, Peijun Huang ${ }^{1,2}$, Puwen Huang ${ }^{3}$, Hong Wang ${ }^{4^{*}}$ and Shiyang Pan ${ }^{1,2^{*}}$

\begin{abstract}
Background: The Response Evaluation Criteria in Solid Tumors (RECIST) guideline and Common Terminology Criteria for Adverse Events (CTCAE) criteria are used to assess chemotherapy efficiency and toxicity in patients with advanced lung cancer. However, no real-time, synchronous indicators that can evaluate chemotherapy outcomes are available. We wanted to evaluate tumor response and toxicity in advanced lung cancer chemotherapy by using a novel synchronous strategy.

Results: We enrolled 316 patients with advanced lung cancer who were treated with cisplatin-based therapy and followed up them for 3 years. Plasma was obtained before and after every chemotherapy cycle. We quantitative assayed total plasma DNA and methylation of the APC/RASSF1A genes. Four parameters were assessed: methylation level before chemotherapy (meth $\mathrm{h}$ ), methylation level $24 \mathrm{~h}$ after chemotherapy (meth $\mathrm{h}_{24} \mathrm{~h}$ ), total plasma DNA concentration before chemotherapy $\left(\mathrm{DNA}_{0} \mathrm{~h}\right.$ ), and total plasma DNA concentration $24 \mathrm{~h}$ after chemotherapy $\left(D_{N A} A_{24}\right)$. When meth $24 \mathrm{~h}>$ meth $_{0} \mathrm{~h}$ of at least one gene was used to predict tumor response, the correct prediction rate was $82.4 \%$. Additionally, patients for whom $\mathrm{DNA}_{24} \mathrm{~h} / \mathrm{DNA} \mathrm{A}_{\mathrm{h}} \leq 2$ had mild toxicities. Therefore, meth $_{24} \mathrm{~h}>$ meth $_{0} \mathrm{~h}$ and $\mathrm{DNA}_{24} \mathrm{~h} / \mathrm{DNA} \mathrm{A}_{\mathrm{h}} \leq 2$ were defined as criteria for better tumor response and fewer adverse events with a high correct prediction rate (84.7\%).

Conclusions: Quantitative analysis of total plasma DNA and plasma APC/RASSFFA methylation provide a real-time synchronous rapid monitoring indicator for therapeutic outcomes of advanced lung cancer, which could be a reference or supplementary guidelines in evaluating chemotherapy effects.
\end{abstract}

Keywords: Hypermethylation, Advanced lung cancer, Circulating DNA, APC, RASSFIA

\section{Background}

Patients with advanced lung cancer (ALC) are usually diagnosed after metastasis has occurred and therefore require chemotherapy. However, the high mortality rate and low 5-year survival rate are partly because of resistance to currently available chemotherapy regimens and ineffective monitoring methods for chemotherapy efficacy [1-9].

\footnotetext{
* Correspondence: hongwang@njmu.edu.cn; sypan@njmu.edu.cn

${ }^{\dagger}$ Equal contributors

${ }^{4}$ Department of Respiratory Medicine, The First Affiliated Hospital of Nanjing Medical University, Nanjing 210029, China

'Department of Laboratory Medicine, The First Affiliated Hospital of Nanjing Medical University, Nanjing 210029, China

Full list of author information is available at the end of the article
}

Several years ago, scholars suggested the notion of realtime apoptosis monitoring, the key point of which was the necessity to find a real-time monitor to provide the information about whether the chemotherapy was working [10]. The current Response Evaluation Criteria in Solid Tumors (RECIST) guideline, which is based on tumor size measured by chest X-ray or CT scan, and widely used tumor markers assay (such as carcinoembryonic antigen (CEA) and neuronal specific enolase (NSE)) are not sensitive enough to monitor chemotherapy effects in an individual patient because these markers require more than a month after chemotherapy to provide the information of 
interest. Consequently, no synchronous indicator that can rapidly evaluate chemotherapy outcomes is available.

Reportedly, total circulating DNA, derived from necrotic or apoptotic cells, can come from both normal cells and tumor cells. In a normal state, total circulating DNA is at a low level-mainly from a few apoptotic normal cells (usually lymphocytes and other nucleated cells) [11]. However, when both normal and tumor cells are killed by chemotherapy drugs, total circulating DNA will obviously increase; DNA from the normal cells will reflect the side effects of the drugs. Because aberrant genes hypermethylation usually occurs in neoplastic and abnormally differentiated cells [12-15], elevated gene methylation levels will be present if many cancer cells are killed by chemotherapy drugs (Additional file 1: Figure S1). Therefore, circulating tumor DNA with abnormal methylation patterns can be detected with a notable degree of specificity, even in the presence of excess DNA from normal cells. This was the start point for the present study to use total circulating DNA and methylation assays as indicators of the efficacy of chemotherapy in ALC patients.

Though many studies have been interested in the relationship between prognosis and methylation levels in tumor suppressor genes (TSGs), research that focuses on indicators that can simultaneously monitor not only tumor response but also toxicity after chemotherapy is rare. We designed this prospective research to present a detailed study on the quantitative dynamic alteration of APC/RASSF1A methylation levels before and after chemotherapy cycles and to combine assays of $A P C /$ RASSF1A methylation and total plasma DNA in the hope of providing a new strategy to monitor efficiency and toxicity of chemotherapy in ALC.

\section{Results}

Methylation levels increased $24 \mathrm{~h}$ after cisplatin administration in A549 cells and in tumor-bearing nude mice

To determine whether APC or RASSF1A gene promoters were methylated in A549 cells, we first assayed the methylation status of this cell line compared with $\mathrm{H} 460$ cells, which acted as a positive control. Ct values of APC and RASSF1A were 28.5 and 29.7 for $\mathrm{H} 460$ and 28.2 and 29.6 for A549, respectively, demonstrating positive methylation of APC and RASSF1A in A549 cells (Additional file 2: Figure S2).

A549 cell supernatant was tested for its methylation status at $6,12,24,48$, and $72 \mathrm{~h}$ after treatment with different concentrations of cisplatin (Fig. 1). First, an 3-(4,5dimethyl-2-thiazolyl)-2, 5-diphenyl-2H-tetrazolium bromide (MTT) assay (Fig. 1a) indicated that A549 cells were sensitive to $5 \mathrm{mg} / \mathrm{ml}$ cisplatin (inhibition rate $>50 \%$ ). Second, under this optimal cisplatin dose $(5 \mathrm{mg} / \mathrm{ml})$, methylation of $A P C$ or RASSF1A peaked at $24 \mathrm{~h}$ (Fig. 1b, c).

For a better understanding of changes in methylation status of the two genes after cisplatin treatment, we used a tumor-bearing nude mouse model (Fig. 1d, e). The methylation rates of APC or RASSF1A in the plasma of tumor-bearing nude mice were highest at $24 \mathrm{~h}$ after injection. Biopsies showed that most tumor cells in the tissues of group 1 (treated with cisplatin) were dead, whereas tumor cells in group 2 (treated with normal saline) were still proliferating (Fig. 1f, g).

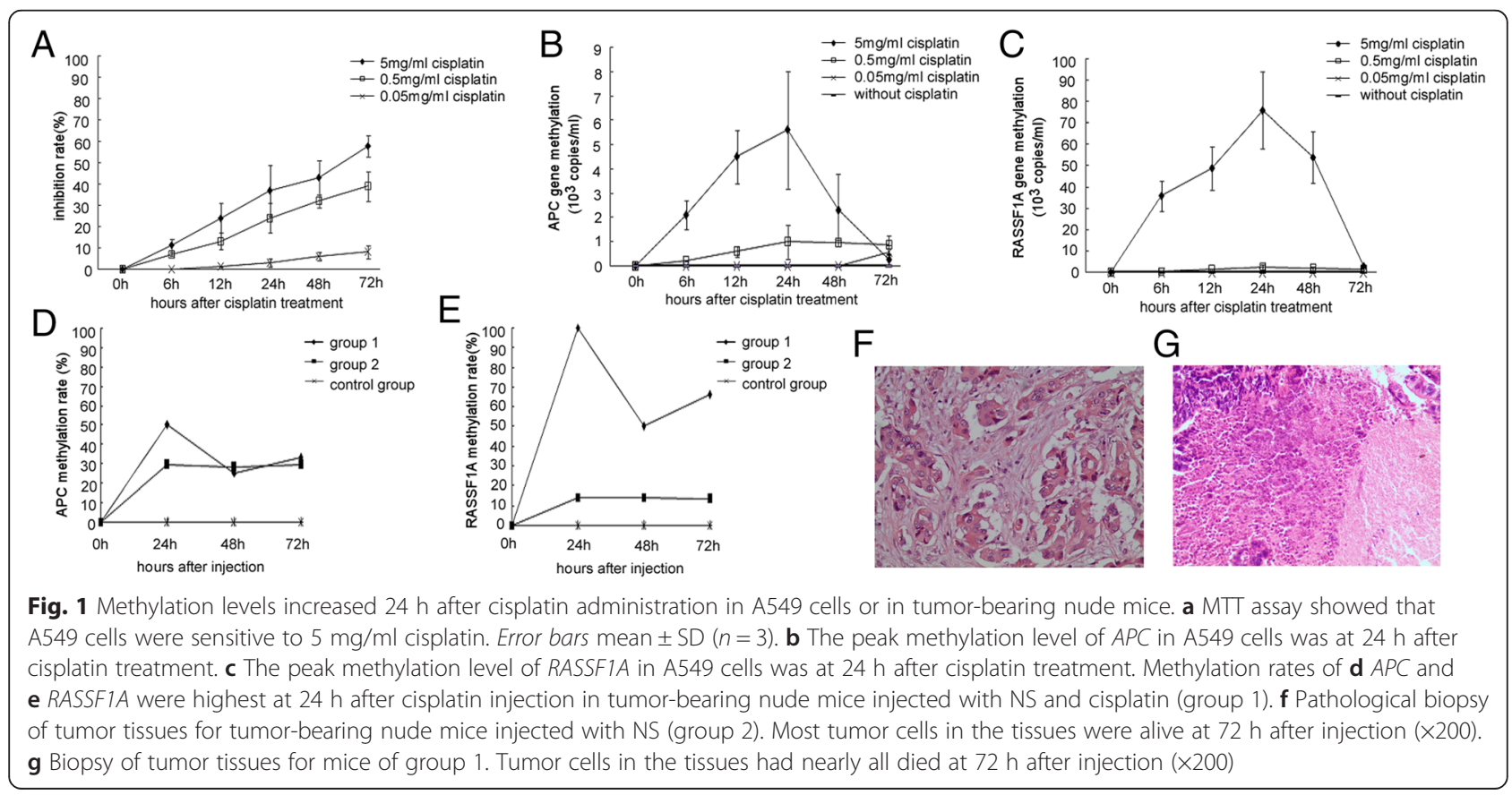




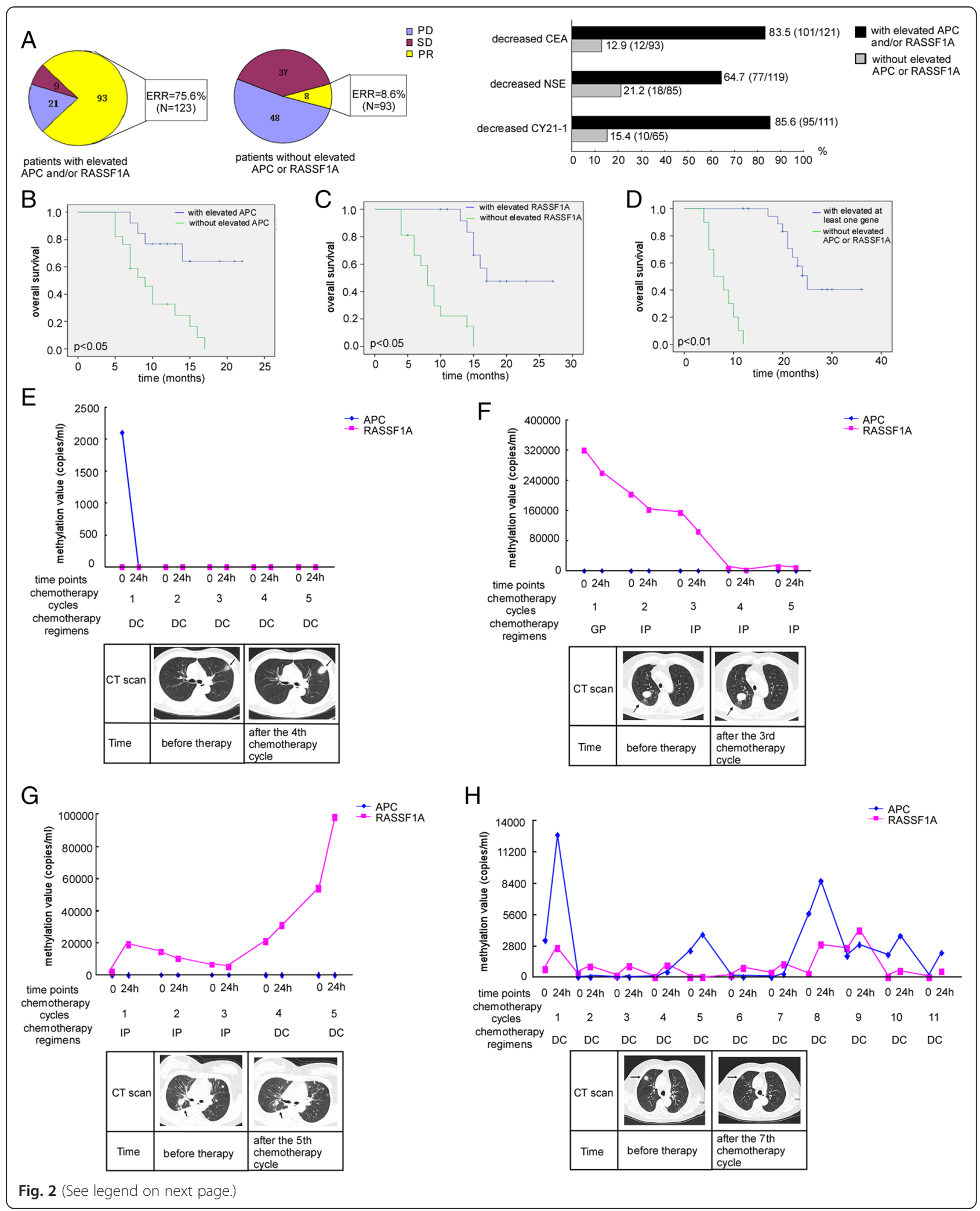


(See figure on previous page.)

Fig. 2 Elevated methylation level after cisplatin-based chemotherapy was correlated with good tumor response in ALC patients of training study. a Tumor response evaluation and tumor markers levels. In patients with elevated APC and/or RASSF1A methylation level, the efficient response rate (ERR) was higher; most cases had decreased tumor markers levels. b Kaplan-Meier curve for OS of patients with and without elevated APC methylation levels (median OS, 18 vs. 9 months, $P<0.05$ ). c Kaplan-Meier curve for OS rates of patients with and without upregulated RASSF1A methylation levels (median OS, 20 vs. 8 months, $P<0.05$ ). d Kaplan-Meier curves for OS rates of patients with elevated methylation levels of at least one gene and those without increased APC or RASSFIA methylation (median OS, 25 vs. 6 months, $P<0.01$ ). e-h Methylation status and CT scan images of four representative patients. e, f Two patients died within 4 and 5 months of diagnosis, respectively. $\mathbf{g}$, $\mathbf{h}$ Two patients remained alive during this study

\section{Elevated methylation level after cisplatin-based chemotherapy was correlated with good tumor response in ALC patients of training study}

Before chemotherapy, methylation frequencies of $A P C$ and/or RASSF1A were $48.9 \%(46 / 94)$ in adenocarcinoma, $50.0 \%(28 / 56)$ in squamous carcinoma, and $39.4 \%$ $(26 / 66)$ in other histological types. After two chemotherapy cycles, 123 patients had elevated $A P C$ and/or RASSF1A methylation (elevated gene methylation means the methylation level at $24 \mathrm{~h}\left[\mathrm{meth}_{24 \mathrm{~h}}\right.$ ] after the chemotherapy cycle was higher than that before chemotherapy $\left[\right.$ meth $\left._{0 \mathrm{~h}}\right]$, that is, meth ${ }_{24 \mathrm{~h}}>$ meth $\left._{0 \mathrm{~h}}\right)$. The efficient response rate (ERR) was $75.6 \%$ (93/123). Among the 123 patients, there were $83.5 \%$ (101/121), $64.7 \%$ (77/119), and $85.6 \%(95 / 111)$ cases whose CEA, NSE, and CY211 levels decreased. In the remaining 93 patients, who were without elevated APC/RASSF1A methylation, the ERR was $8.6 \%$ (8/93), significantly lower than those with meth $_{24 \mathrm{~h}}>$ meth $_{0 \mathrm{~h}}$ of at least one gene $(P<0.01)$. CEA, NSE, and CY21-1 levels decreased in $12.9 \%(12 / 93)$, $21.2 \%(18 / 85)$, and $15.4 \%(10 / 65)$ of these 93 patients (Fig. 2a). When we used meth ${ }_{24} \mathrm{~h}>$ meth $_{0 \mathrm{~h}}$ of at least one gene to predict tumor response, the correct prediction rate was $82.4 \%[(93+37+48) / 216]$.

We performed overall survival (OS) rate analyses according to increases in gene methylation levels after chemotherapy (Fig. 2b-d). The median survival was different between patients with methylation level elevation and those without elevation of APC or RASSF1A methylation.

The above results seemed to suggest that the meth $24 \mathrm{~h}>$ meth $_{0 \mathrm{~h}}$ of at least one gene is correlated with good response to cisplatin-based chemotherapy in ALC patients. Large amounts of clinical data taken over a 3-year followup also confirmed this opinion (Fig. 2e-h).

\section{Elevated total plasma DNA after cisplatin-based chemotherapy was correlated with the adverse events grade in ALC patients of training study}

Toxicities were evaluated after the first chemotherapy. From 216 paired plasma samples (before and 24 h after medication), we got the changes of total plasma DNA: total plasma DNA concentration at $24 \mathrm{~h}$ after medication $\left(\mathrm{DNA}_{24 \mathrm{~h}}\right)$ was less than or equal to twofolds of that before medication $\left(\mathrm{DNA}_{0} \mathrm{~h}\right)$ in 132 cases $\left(\mathrm{DNA}_{24} \mathrm{~h} /\right.$
$\left.\mathrm{DNA}_{0 \mathrm{~h}} \leq 2\right)$ and $\mathrm{DNA}_{24} \mathrm{~h}$ was more than twofolds of $\mathrm{DNA}_{0 \mathrm{~h}}$ in 84 cases $\left(\mathrm{DNA}_{24 \mathrm{~h}} / \mathrm{DNA}_{0 \mathrm{~h}}>2\right)$. Toxicities of platinum-based regimens, especially hepatotoxicity, nephrotoxicity, and gastrointestinal symptoms, mainly occurred in the $84 \mathrm{DNA}_{24 \mathrm{~h}} / \mathrm{DNA}_{0 \mathrm{~h}}>2$ cases (Fig. 3a). The incidence of adverse events in the $D^{2} A_{24} h /$ $\mathrm{DNA}_{0} \mathrm{~h}>2$ case group was higher than that in the $\mathrm{DNA}_{24 \mathrm{~h}} / \mathrm{DNA}_{0 \mathrm{~h}} \leq 2$ case group (39.53 vs. $28.69 \%, P<$ 0.05). Especially, the incidence of adverse events above grade 1 in the $\mathrm{DNA}_{24 \mathrm{~h}} / \mathrm{DNA}_{0 \mathrm{~h}}>2$ case group was significantly elevated compared with that in the $\mathrm{DNA}_{24} \mathrm{~h} /$ $\mathrm{DNA}_{0 \mathrm{~h}} \leq 2$ case group (13.18 vs. $6.77 \%, P<0.05$, Fig. $\left.3 \mathrm{~b}\right)$.

\section{Combined APC/RASSF1A methylation and total plasma DNA assay was consistent with clinical judgment in ALC patients of training study}

After the second chemotherapy cycle, we found 123 patients who were meth ${ }_{24} \mathrm{~h}>$ meth $_{0} \mathrm{~h}$ for $A P C$ and/or RASSF1A, 93 who were meth $_{24} \mathrm{~h} \leq$ meth $_{0 \mathrm{~h}}$ for both genes, 67 were $\mathrm{DNA}_{24} \mathrm{~h} / \mathrm{DNA}_{0 \mathrm{~h}}>2$ patients, and 149 were $\mathrm{DNA}_{24} \mathrm{~h}_{\mathrm{h}} / \mathrm{DNA}_{0} \mathrm{~h} \leq 2$ patients. Monitoring performance of combined APC/RASSF1A methylation and total plasma DNA assay, and the clinical judgment of tumor response and toxicity degree, is shown in Fig. 4a. Patients in quadrant I to quadrant IV were 47, 26, 67, and 76 , respectively. In quadrant I, clinical judgment (tumor response and toxicity) was consistent with combined methylation and total plasma DNA assay in 38 cases. The coincidence rate was $80.9 \%(38 / 47)$. Likewise, the coincidence rates were $84.6 \%(22 / 26), 85.1 \%(57 / 67)$, and $86.8 \%(66 / 76)$ in quadrants II to IV, respectively. Therefore, the use of combined APC/RASSF $1 A$ methylation and total plasma DNA assay to predict chemotherapy outcome gave a correct prediction rate of $84.7 \%[(22+57+38+66) / 216]$.

\section{Further confirmation of the combined indicator in validation study}

After the second chemotherapy cycle, 54 patients were judged to have complete response (CR)/partial response (PR) and mild adverse events; of these, $85.2 \%(46 / 54)$ had "meth ${ }_{24} \mathrm{~h}>$ meth $_{0} \mathrm{~h}$ " of at least one gene and " $\mathrm{DNA}_{24} \mathrm{~h} / \mathrm{DNA}_{0} \mathrm{~h} \leq 2$ ". In contrast, 28 patients had stable disease (SD)/progressive disease (PD) and 


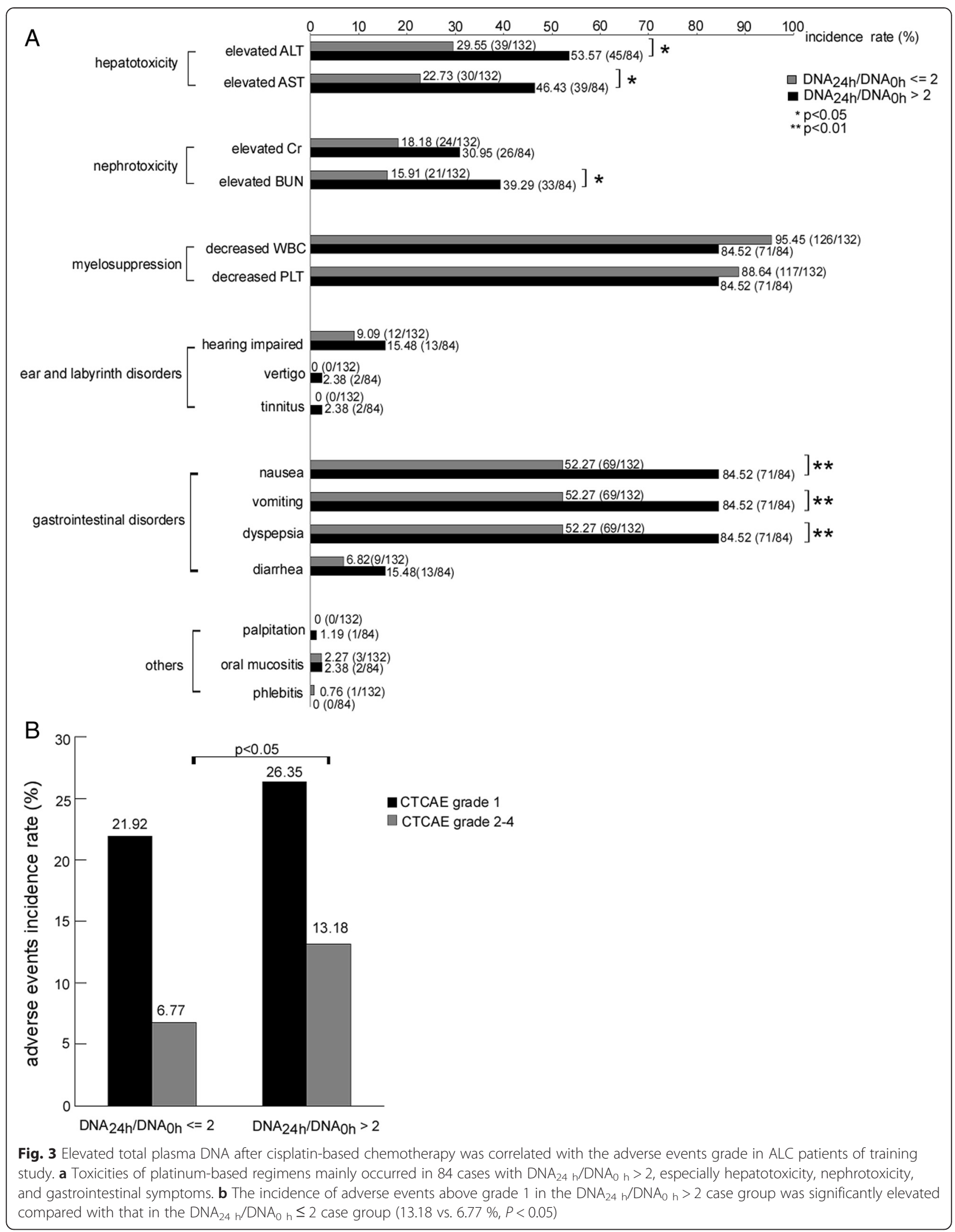




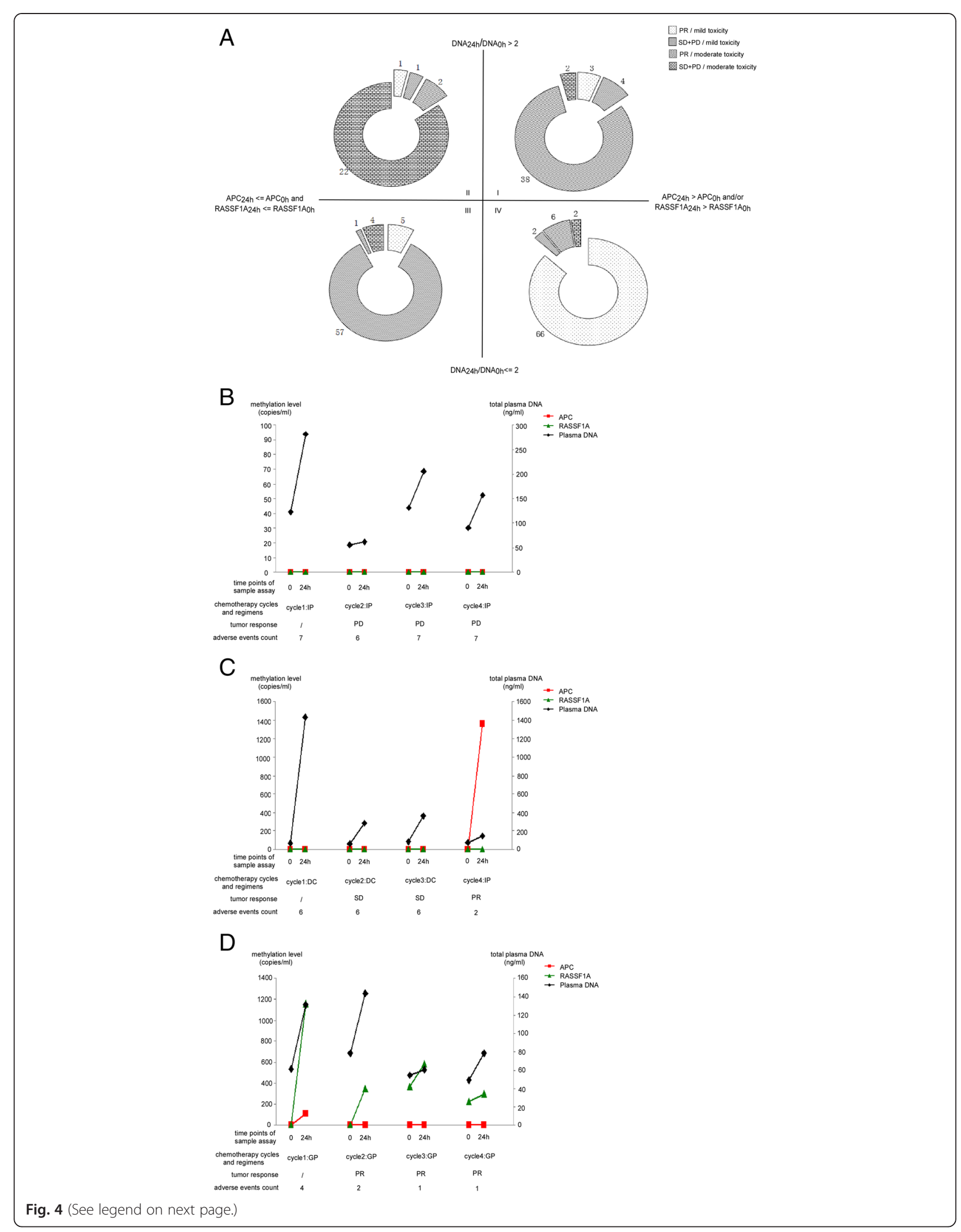


(See figure on previous page.)

Fig. 4 Combined APC/RASSF1A methylation and total plasma DNA assay was consistent with clinical judgment in ALC patients. a Patients with different methylation status and plasma DNA level had different tumor response and degrees of adverse events. The coincidence rates were $80.9,84.6,85.1$, and $86.8 \%$ in quadrants I to IV, respectively. b-d Methylation status, plasma DNA level, and some clinical information of three patients in the validation model. b A male patient died within 5 months of diagnosis. c A female patient had been alive for 36 months by the end of follow-up. $\mathbf{d}$ A patient had been alive nearly 24 months by the end of follow-up

moderate/severe adverse events, of whom $82.1 \%(23 / 28)$ showed no APC/RASSF1A methylation elevation or had very high $\mathrm{DNA}_{24} \mathrm{~h}$. Ten patients have $\mathrm{CR} / \mathrm{PR}$ and moderate/severe adverse events, $80 \%(8 / 10)$ had "meth ${ }_{24} \mathrm{~h}>$ meth $h_{0}$ " of at least one gene and $\mathrm{DNA}_{24} / \mathrm{DNA}_{0} \mathrm{~h}>2$. Eight patients have SD/PD and mild adverse events, $75 \%$ (6/8) showed no APC/RASSF1A methylation elevation and "DNA ${ }_{24} \mathrm{~h} / \mathrm{DNA}_{0 \mathrm{~h}} \leq 2$ ". Dynamic observation of cycles during follow-up was also analyzed. Figure $4 \mathrm{~b}-\mathrm{d}$ shows changes in total plasma DNA, APC/RASSF1A methylation, and clinical adverse events from three randomly chosen patients. This information also confirmed that patients with "meth ${ }_{24 \mathrm{~h}}>$ meth $_{0}$ h" of at least one gene and "DNA ${ }_{24} \mathrm{~h} /$ $\mathrm{DNA}_{0 \mathrm{~h}} \leq 2$ " had better tumor response and fewer adverse events.

\section{Discussion}

Chemotherapy is usually the treatment of choice to improve the quality of life and prolong survival time of patients with advanced cancers. The response of malignant tumors to chemotherapy varies, and some clinical trials have shown that patients with advanced cancer who received personalized chemotherapeutic regimens or drug doses fared better than those treated with standard chemotherapy [16, 17], which has led to increased focus on personalized medicine [18]. However, existing detection means are not sensitive and timely enough to provide adequate information about chemosensitivity.

Cell death reportedly results in the release of DNA into the circulation, which peaks at $24 \mathrm{~h}$ and gradually declines $[19,20]$. Results of cell lines and nude mouse studies showed us the dynamic changes of $A P C$ and RASSF1A methylation on both lung adenocarcinoma cell line (A549) and large cell lung cancer cell line (H460) and indicated that peak methylation increase is also at $24 \mathrm{~h}$ after cisplatin administration.
Many studies have shown the high methylation frequency of $A P C$ and RASSF1A in the plasma of lung cancer patients [21-28]. Therefore, we chose the two genes and originated the duplex quantitative methylation specific PCR (qMSP) method to assess their promoter methylation. The feature of this new method is simultaneous detection of both genes' methylation. Several studies have found differences in the methylation frequencies of $A P C$ or RASSF1A among the particular histological types of lung cancer [29-33]. The reason of these conflicting findings may be the difference in detection sites of the two genes' promoters. Moreover, we offer both $A P C$ and/or RASSF1A to diminish the influence of histological type that might be caused by using a single gene. Additionally, we compared methylation frequencies of APC/RASSF1A with other five studies [32, 34-37] (Additional file 3: Table S1). The results showed no significant sample selection bias in the present study. Therefore, our APC/RASSF1A methylation application for lung cancer prognosis is reliable.

Therefore, we detected the quantitative methylation levels of $A P C$ and RASSF1A before and $24 \mathrm{~h}$ after the chemotherapy cycles to evaluate tumor response in lung cancer patients. According to the results, we confirmed our hypothesis that meth $24 \mathrm{~h}>$ meth $_{0 \mathrm{~h}}$ is a predictor of sensitivity to cisplatin-based chemotherapy in lung cancer patients. The explanation of this hypothesis is as follows: if the tumor cells are sensitive to chemotherapy drugs, they will be heavily destroyed and lead to a temporary mass release of DNA. Therefore, at $24 \mathrm{~h}$ after medication, circulating DNA levels will be higher than that before medication. As indicated in quadrant IV of Fig. 4a, circulating DNA of patients with good drug response was mainly from cancer cells, while circulating DNA of patients with severe toxicity (quadrant II, Fig. 4a) was mainly from healthy cells.

Moreover, Kaplan-Meier analysis and the dynamic methylation monitoring of patients also indicate that

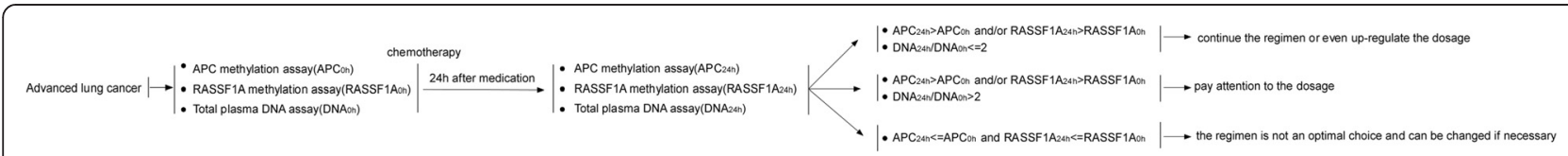

Fig. 5 The strategy of using combined APC/RASSFIA methylation and total plasma DNA to assess chemotherapy response and toxicity and to adjust regimens 
patients with increased $A P C$ or RASSF1A methylation levels after cisplatin-based chemotherapy have better outcomes. Additionally, although a patient's tumor lesion may undergo alterations which are characteristics of remission after effective therapy, the symptoms do not typically present in time. So before we can observe obvious symptoms and signs, most patients $(82.4 \%)$ can use $A P C$ and RASSF1A methylation assay after every chemotherapy cycle to predict tumor response. Therefore, methylation detection of plasma at $24 \mathrm{~h}$ after medication is a promising earlier and timing indicator than some tumor markers or CT scanning.

At the last part of the training study, we assayed total plasma DNA to monitor toxicity of chemotherapy in ALC patients. This content shows that toxicity is more common in patients with excessively elevated plasma DNA $\left(\mathrm{DNA}_{24}{ }_{\mathrm{h}} / \mathrm{DNA}_{0 \mathrm{~h}}>2\right)$. Therefore, when combined with APC/RASSF1A methylation, there were three models:

(1) APC and/or RASSF1A methylation levels increase with $D N A_{24}{ }_{h} / D N A_{O}{ }_{h} \leq 2$. This model indicates that patients will benefit from this chemotherapy regimen without severe toxicity. Therefore, to get a better chemotherapy effect, patients can receive higher dosage of chemotherapy drugs while monitoring both total plasma DNA and $A P C /$ RASSF1A methylation levels.

(2) APC and/or RASSF1A methylation levels increase with $D N A_{24}{ }_{h} / D N A_{O} h>2$. In this model, good tumor response and obvious toxicity co-exist. Thus, dosage may need adjustment (usually downward) to avoid severe side effects.

(3) APC and RASSF1A methylation levels never increase no matter how total plasma DNA changes. In this model, tumor cells are not sensitive to the chemotherapy regimen. Hence, the regimen is not an optimal choice and should be changed immediately.

Based on the above results of this study, we offer a new strategy to assess the efficiency and toxicity of chemotherapy for ALC (Fig. 5), according to which clinicians can adjust chemotherapy regimens in time.

\section{Conclusions}

We were able to demonstrate that quantitative assay of total plasma DNA and APC/RASSF1A methylation levels can rapidly and simultaneously predict tumor response and toxicity to cisplatin-based chemotherapy in ALC patients. Especially, the quantitative methylation assay of TSG can show chemosensitivity $24 \mathrm{~h}$ after chemotherapy cycles, which is much faster than the imaging-based examinations used in the RECIST guideline. Furthermore, plasma DNA and TSG methylation assays are simple and non-invasive tools, convenient for follow-up and repeated sample collection. The new strategy shown in Fig. 5 may therefore provide a reference or supplement to guidelines in evaluating chemotherapy effects.

\section{Methods}

\section{Cell culture, MTT assay, and supernatant collection}

Human lung adenocarcinoma A549 cells (Shanghai Institutes for Biological Sciences, China) were seeded in triplicate at a density of $1.5 \times 10^{4}$ cells $/ 100 \mu \mathrm{l}$ in 96-well plates and grown at $37{ }^{\circ} \mathrm{C}$ in a humidified atmosphere containing $5 \% \mathrm{CO}_{2}$. After $24 \mathrm{~h}, 100 \mu \mathrm{l} /$ well cisplatin was added to the cells at three final concentrations $(5,0.5$, and $0.05 \mathrm{mg} / \mathrm{ml})$. Cells without cisplatin treatment served as controls. At $0,6,12,24$, 48 , and $72 \mathrm{~h}$ after administration, the culture supernatant was collected. Then, $20 \mu \mathrm{l}$ MTT $(5 \mathrm{mg} / \mathrm{ml})$ was added to each well, and the plate was incubated at $37{ }^{\circ} \mathrm{C}$ for another $4 \mathrm{~h}$, after which $10 \%$ HCL-SDS $(100 \mu \mathrm{l})$ was added to each well. Cell proliferation was determined using a 96-well plate reader to record the absorbance at $570 \mathrm{~nm}$. The inhibition percentage of A549 cell proliferation was calculated using the following formula: inhibition rate $=([$ absorbance of control well]-[absorbance of administration well])/ [absorbance of control well] $\times 100 \%$. Data are expressed as mean $\pm \mathrm{SD}$ of triplicate wells and are representative of at least two independent experiments.

\section{Nude mouse model of lung adenocarcinoma and blood or tumor tissues collection}

Twenty-four nude mice were purchased from Shanghai SLAC Laboratory Animal Company. Eight mice were designated as control group, and two of which died. The other 16 nude mice were used to establish a lung adenocarcinoma model by subcutaneous injection of $2 \times 10^{6}$ A549 cells in the hind legs. When tumor diameters were more than $5 \mathrm{~mm}$ after 25 days, the 16 tumor-bearing nude mice were randomly divided into two groups: group 1 consisted of eight tumor-bearing nude mice that were intratumorally injected with $0.2 \mathrm{ml}$ normal saline (NS) containing $8 \mu \mathrm{g}$ cisplatin per gram of mouse body weight for three consecutive days. Group 2 consisted of eight tumor-bearing nude mice that were intratumorally injected with $0.2 \mathrm{ml} \mathrm{NS}$ for three consecutive days.

Blood and tumor tissues of the four groups and controls were collected at 24,48 , and $72 \mathrm{~h}$ after administration. To obtain plasma, the blood specimens were centrifuged in two steps at $4{ }^{\circ} \mathrm{C}(3000 \mathrm{rpm}$ for $10 \mathrm{~min}$ and 16,000 rpm for $10 \mathrm{~min}$ ) [19]. The tumor tissues were prepared by H\&E staining. 


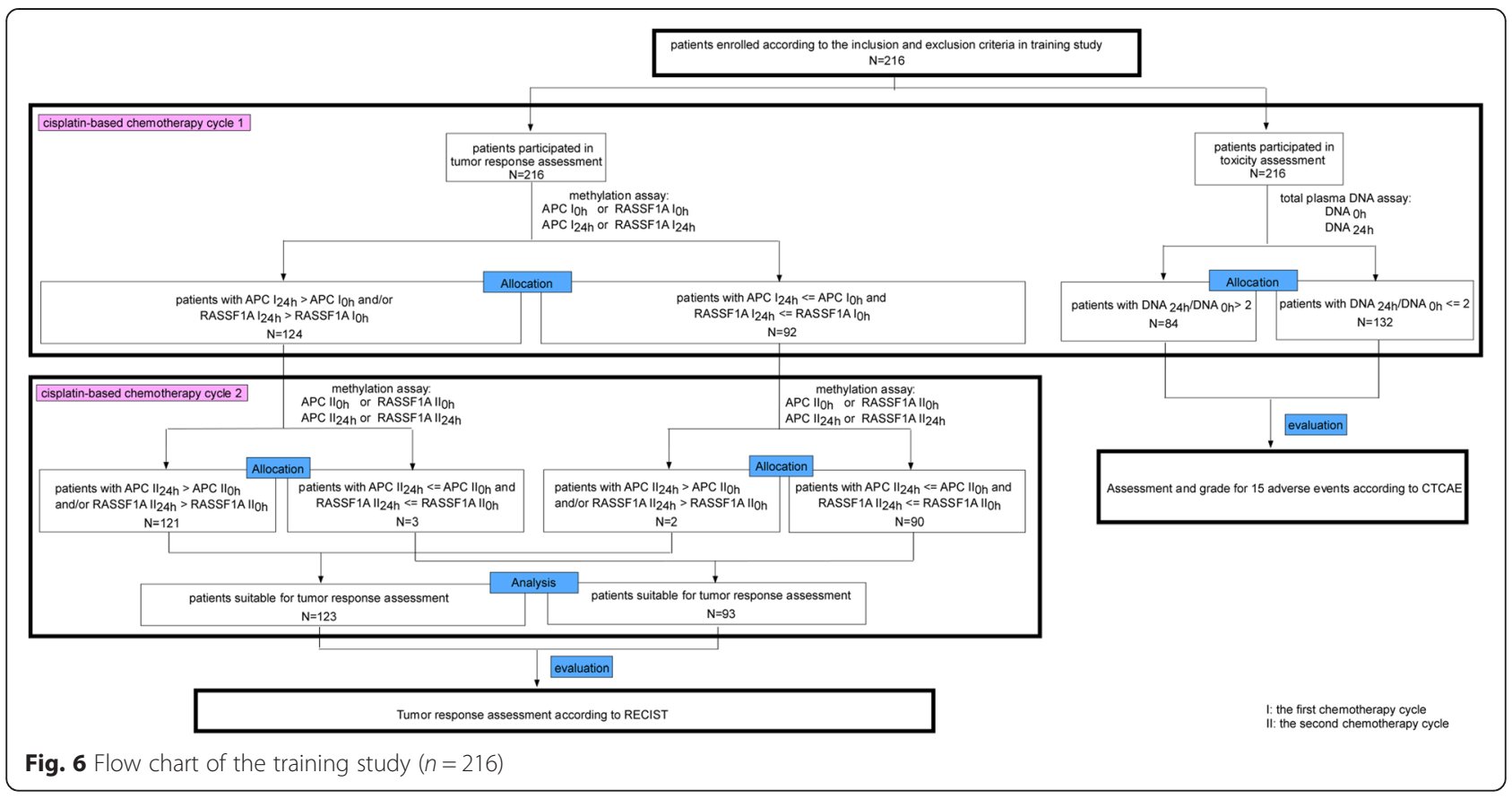

\section{Advanced lung cancer patients}

Patients with stages IIIb and IV ALC were recruited from the Department of Oncology of the First Affiliated Hospital of Nanjing Medical University (China) from October 2007 to June 2009. All patients were followed until November 2010. Inclusion criteria were (1) histologically or cytology confirmed lung cancer, (2) newly diagnosed disease according to the staging system of the 2002 American Joint Committee on Cancer (AJCC), (3) an age of 18-80 years, (4) unresectable or metastatic disease, (5) measurable disease, (6) Eastern Cooperative Oncology Group (ECOG) performance status 0-2, (7) life expectancy $>3$ months, (8) no contraindication for chemotherapy, and (9) cisplatin-based regimens for two initial cycles. The exclusion criteria were as follows: (1) a history of previous malignant neoplasms or other concomitant malignant diseases; (2) a history of surgery, chemotherapy, and radiotherapy; and (3) refusal to have blood drawn for times needed for this study. All patients gave informed consent prior to specimen collection according to the study, which was reviewed and approved by the Committee on the Ethics of Treatment of Human Subjects of The First Affiliated Hospital of Nanjing Medical University. Two hundred and sixteen patients were included in the training study, and flow chart of which is presented in Fig. 6. Another 100 patients were enrolled in the validation study. The patients' characteristics are listed in Additional file 4: Table S2.

The blood samples in EDTA-containing tubes, which were used to perform total plasma DNA and methylation assays, were collected from these patients before and $24 \mathrm{~h}$ after every chemotherapy cycle and were centrifuged in two steps at $4{ }^{\circ} \mathrm{C}(3000 \mathrm{rpm}$ for $10 \mathrm{~min}$ and $16,000 \mathrm{rpm}$ for $10 \mathrm{~min}$ ) to obtain plasma.

\section{Evaluation of chemotherapy efficiency and toxicity}

All the patients were followed for at least four chemotherapy cycles. Chemotherapy regimens were IP (irinotecan/ cisplatin), DC (docetaxel/cisplatin), and GP (gemcitabine/ cisplatin). Chemotherapy efficacy was evaluated by tumor response according to the Response Evaluation Criteria in Solid Tumors (RECIST1.1) [38] 50-60 days after the first cycle. The main evaluation contents were efficient response rate (ERR), tumor markers (detected 2 months after the first cycle), and overall survival (OS). Efficient response included complete response (CR) and partial response (PR). Non-efficient response included stable disease (SD) and progressive disease (PD). Tumor markers were CEA, NSE, and CY21-1, which are the most commonly used markers in lung cancer. Fifteen main toxicities were assessed and graded according to the Common Terminology Criteria for Adverse Events (CTCAE, Version 4.0) after a single chemotherapy cycle.

\section{DNA extraction from culture supernatant or plasma}

DNA was extracted from $200 \mu \mathrm{l}$ cell culture supernatant or mouse and patient plasma using the BilaTest DNA Kit (Bilatec, Viernheim, Germany), according to the manufacturer's recommendations. Briefly, $200 \mu \mathrm{l}$ of specimen was mixed thoroughly with lysis solution, poly(A)RNA/protease solution, and beads/binding buffer, and tubes were placed on a magnet. After discarding the supernatant, the DNA 
was washed twice with washing solution and then eluted with $40 \mu \mathrm{l}$ of elution buffer.

\section{Total plasma DNA assay}

Duplex real-time PCR was performed to detect total plasma DNA concentrations, which is described in our previous study [39].

\section{Duplex qMSP assay of APC and RASSF1A promoter methylation levels}

The NCI-H460 cell line was introduced into this study as positive control for methylation of APC and RASSF1A, as previously described [39]. External standard curves were prepared by serial diluted calibrators and contained $1.5 \times 10^{5}, 1.5 \times 10^{4}, 1.5 \times 10^{3}$, and $1.5 \times 10^{2}$ copies $/ \mathrm{ml}$ of H460 cell DNA using the plasma of a healthy person as solution matrix. The extracted DNA samples $(50 \mu \mathrm{l})$, including that of the cell culture supernatant, nude mice, patients, and $\mathrm{H} 460$ cells, were modified by sodium bisulfate using a CpGenome DNA Modification Kit (Chemicon, USA) based on the principles and procedure previously described by Herman [40]. To fully utilize the trace quantity of modified DNA, we developed a duplex qMSP to measure APC and RASSF1A simultaneously in the same tube. Each amplification mix $(50 \mu \mathrm{l})$ contained sample DNA ( $5 \mu \mathrm{l}$ ) with components supplied in the Takara Ex Taq R-PCR Version 2.1 kit (Takara, Dalian, China). Each reaction contained $10 \mu \mathrm{l}$ of $5 \times$ realtime PCR buffer, $400 \mu \mathrm{M}$ each deoxynucleotide triphosphate, $2 \mathrm{mM} \mathrm{MgCl} 2,200 \mathrm{nM}$ each primer, $170 \mathrm{nM}$ each probe, and $2 \mathrm{U}$ Takara Ex Taq HS. All the primers and probes used in this protocol were designed by Primer Express Software Version 3.0 and are listed in Additional file 5: Table S3. Amplification and real-time measurement were performed in an Applied Biosystems 7500 Sequence Detector (Applied Biosystems, CA, USA) under the following conditions: $1 \mathrm{~min}$ at $95^{\circ} \mathrm{C}$ followed by 55 cycles of $5 \mathrm{~s}$ at $95{ }^{\circ} \mathrm{C}$ and $34 \mathrm{~s}$ at $60{ }^{\circ} \mathrm{C}$. Data obtained during 55 cycles of amplification were analyzed. All samples were tested in triplicate. Blood samples pre- and postchemotherapy from one patient were analyzed simultaneously. Data are expressed as median and interquartile.

\section{Statistical analysis}

All statistical analyses were carried out using Stata9.1 and SPSS13.0 software. Two-way ANOVA tests were used to compare methylation levels between treatment and control groups of A549 cells when three time points were assessed. The methylation rates between tumor-bearing nude mice groups were analyzed using the Fisher's exact test. Quantitative methylated genes before and after the first chemotherapy cycle was assessed by the Wilcoxon matched-pairs signed-rank test. Differences between groups were analyzed using the Kruskal-Wallis signed- rank test. Survival curves were calculated using the Kaplan-Meier method, and comparisons were performed by the log-rank test. $P<0.05$ was considered significant.

\section{Additional files}

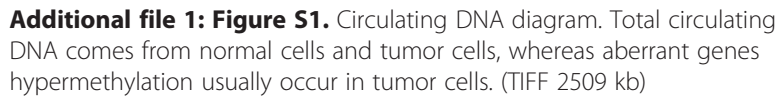

Additional file 2: Figure S2. Methylation amplification curves for APC or RASSF1A in A549 cells. (A) Methylation amplification curves for APC gene promoter. (B) Methylation amplification curves for RASSF1A gene promoter. The Ct values for APC and RASSF1A gene amplification in A549 cells were close to those of the $\mathrm{H} 460$ positive control cells. (TIFF $1393 \mathrm{~kb}$ )

Additional file 3: Table S1. Methylation frequency of APC and/or RASSF1A in present study and other 5 articles. (DOCX $80 \mathrm{~kb}$ )

Additional file 4: Table S2. Clinical characteristics of 316 advanced lung cancer patients. (DOCX $18 \mathrm{~kb}$ )

Additional file 5:Table S3. Primers and probes used in duplex qMSP. (DOCX $13.7 \mathrm{~kb})$

\section{Abbreviations}

AJCC: American Joint Committee on Cancer; ALC: advanced lung cancer; CEA: carcinoembryonic antigen; CR: complete response; CTCAE: Common Terminology Criteria for Adverse Events; DC: docetaxel and cisplatin; $\mathrm{DNA}_{0} \mathrm{~h}$ : total plasma DNA concentration before chemotherapy treatment; $\mathrm{DNA}_{24} \mathrm{~h}$ : total plasma DNA concentration at $24 \mathrm{~h}$ after chemotherapy treatment; ECOG: Eastern Cooperative Oncology Group; ERR: efficient response rate; GP: gemcitabine and cisplatin; IP: irinotecan and cisplatin; meth $_{0}$ : methylation level before chemotherapy treatment; meth $_{24 \mathrm{~h}}$ : methylation level at $24 \mathrm{~h}$ after chemotherapy treatment; NS: normal saline; NSE: neuronal specific enolase; OS: overall survival; PD: progressive disease; PR: partial response; RECIST: Response Evaluation Criteria in Solid Tumors; SD: stable disease; TSG: tumor suppressor genes.

\section{Competing interests}

The authors declare that they have no competing interests.

\section{Authors' contributions}

The experiments were conceived and designed by SYP. The experiments were performed by YCL and YG. Data were analyzed by HW, BFZ, WYX, and JXZ. FW, $J X, Y Z, M J Z, L X Z$, and PJH participated in the conduction and coordination of the study. The paper was written by HW and DC. The clinical samples were collected by $Y C L, Y G$, and $P W H$. All authors read and approved the final manuscript.

\section{Acknowledgments}

The authors would like to acknowledge the following funding sources: National Natural Science Foundation of China (No. 81101322, 30972821, 30901262, 81371894), Key Laboratory for Laboratory Medicine of Jiangsu Province of China (No. XK201114), Doctor Supervisor Foundation of Ministry of Education (No. 20113234110012), and A Project Funded by the Priority Academic Program Development of Jiangsu Higher Education Institutions.

\section{Author details}

${ }^{1}$ Department of Laboratory Medicine, The First Affiliated Hospital of Nanjing Medical University, Nanjing 210029, China. ${ }^{2}$ National Key Clinical Department of Laboratory Medicine, Nanjing 210029, China. ${ }^{3}$ Department of Oncology, The First Affiliated Hospital of Nanjing Medical University, Nanjing 210029, China. ${ }^{4}$ Department of Respiratory Medicine, The First Affiliated Hospital of Nanjing Medical University, Nanjing 210029, China.

Received: 9 January 2015 Accepted: 22 October 2015

Published online: 05 November 2015

\section{References}

1. Mascaux C, Peled N, Garg K, Kato Y, Wynes MW, Hirsch FR. Early detection and screening of lung cancer. Expert Rev Mol Diagn. 2010;10:799-815. 
2. Punnoose EA, Atwal S, Liu W, Raja R, Fine BM, Hughes BG, et al. Evaluation of circulating tumor cells and circulating tumor DNA in non-small cell lung cancer: association with clinical endpoints in a phase II clinical trial of pertuzumab and erlotinib. Clin Cancer Res. 2012;18:2391-401.

3. Molina JR, Yang P, Cassivi SD, Schild SE, Adjei AA. Non-small cell lung cancer: epidemiology, risk factors, treatment, and survivorship. Mayo Clin Proc. 2008:83:584-94.

4. Parkin DM, Bray F, Ferlay J, Pisani P. Global cancer statistics, 2002. CA Cancer J Clin. 2005;55:74-108.

5. Sato M, Shames DS, Gazdar AF, Minna JD. A translational view of the molecular pathogenesis of lung cancer. J Thorac Oncol. 2007;2:327-43.

6. Ramirez JL, Rosell R, Taron M, Sanchez-Ronco M, Alberola V, de Las PR, et al. 14-3-3ømethylation in pretreatment serum circulating DNA of cisplatin-plusgemcitabine-treated advanced non-small-cell lung cancer patients predicts survival: The Spanish Lung Cancer Group. J Clin Oncol. 2005;23:9105-12.

7. Allingham-Hawkins D, Lea A, Levine S. ERCC1 expression analysis to guide therapy in non-small cell lung cancer. PLoS Curr. 2010;2:RRN1202.

8. O'Byrne KJ, Barr MP, Gray SG. The role of epigenetics in resistance to cisplatin chemotherapy in lung cancer. Cancers. 2011;3:1426-53.

9. Koomen JM, Haura EB, Bepler G, Sutphen R, Remily-Wood ER, Benson K, et al. Proteomic contributions to personalized cancer care. Mol Cell Proteomics. 2008;7:1780-94.

10. Jain KK. Textbook of personalized medicine. New York: Springer; 2009. p. 186.

11. Gormally E, Caboux E, Vineis P, Hainaut P. Circulating free DNA in plasma or serum as biomarker of carcinogenesis: practical aspects and biological significance. Mutat Res. 2007;635:105-17.

12. Kamat AA, Baldwin M, Urbauer D, Dang D, Han LY, Godwin A, et al. Plasma cell-free DNA in ovarian cancer: an independent prognostic biomarker. Cancer. 2010;116:1918-25.

13. Kumar S, Guleria R, Singh V, Bharti AC, Mohan A, Das BC. Plasma DNA level in predicting therapeutic efficacy in advanced non-small cell lung cancer. Eur Respir J. 2010;36:885-92.

14. Liggett T, Melnikov A, Yi QL, Replogle C, Brand R, Kaul K, et al. Differential methylation of cell-free circulating DNA among patients with pancreatic cancer versus chronic pancreatitis. Cancer. 2010;116:1674-80.

15. Vlassov W, Laktionov PP, Rykova EY. Circulating nucleic acids as a potential source for cancer biomarkers. Curr Mol Med. 2010;10:142-65.

16. Sequist LV, Martins RG, Spigel D, Grunberg SM, Spira A, Jänne PA, et al. First-line gefitinib in patients with advanced non-small-cell lung cancer harboring somatic EGFR mutations. J Clin Oncol. 2008;26:2442-9.

17. Gamelin E, Delva R, Jacob J, Merrouche Y, Raoul JL, Pezet D, et al. Individual fluorouracil dose adjustment based on pharmacokinetic follow-up compared with conventional dosage: results of a multicenter randomized trial of patients with metastatic colorectal cancer. J Clin Oncol. 2008;26:2099-105.

18. Shepherd FA. Molecular selection of patients for first-line treatment of advanced non-small-cell lung cancer with epidermal growth factor inhibitors: not quite ready for prime time. J Clin Oncol. 2008;26:2426-7.

19. Lo YM, Tein MS, Lau TK, Haines CJ, Leung TN, Poon PM, et al. Quantitative analysis of fetal DNA in maternal plasma and serum: implications for noninvasive prenatal diagnosis. Am J Hum Genet. 1998;62:768-75

20. Jahr S, Hentze H, Englisch S, Hardt D, Fackelmayer FO, Hesch RD, et al. DNA fragments in the blood plasma of cancer patients: Quantitations and evidence for their origin from apoptotic and necrotic cells. Cancer Res. 2001;61:1659-65.

21. Hsu HS, Chen TP, Hung CH, Wen CK, Lin RK, Lee HC, et al. Characterization of a multiple epigenetic marker panel for lung cancer detection and risk assessment in plasma. Cancer. 2007;110:2019-26.

22. Rosell R, Cecere F, Santarpia M, Reguart N, Taron M. Predicting the outcome of chemotherapy for lung cancer. Curr Opin Pharmacol. 2006;6:323-31.

23. Brock MV, Hooker CM, Ota-Machida E, Han Y, Guo M, Ames S, et al. DNA methylation markers and early recurrence in stage I lung cancer. N Engl J Med. 2008:358:1118-28.

24. Gu J, Berman D, Lu C, Wistuba II, Roth JA, Frazier M, et al. Aberrant promoter methylation profile and association with survival in patients with non-small cell lung cancer. Clin Cancer Res 2006,12:7329-38.

25. Toyota M, Suzuki H, Yamashita T, Hirata K, Imai K, Tokino T, et al. Cancer epigenomics: implications of DNA methylation in personalized cancer therapy. Cancer Sci. 2009;100:787-91.

26. Ramírez JL, Salazar MF, Gupta J, Sánchez JM, Taron M, Sanchez-Ronco M, et al. Methylation patterns and chemosensitivity in NSCLC. Adv Exp Med Biol. 2006:587:195-209.
27. Fischer JR, Ohnmacht U, Rieger N, Zemaitis M, Stoffregen C, Manegold C, et al. Prognostic significance of RASSF1A promoter methylation on survival of non-small cell lung cancer patients treated with gemcitabine. Lung Cancer. 2007:56:115-23.

28. Buckingham L, Penfield Faber L, Kim A, Liptay M, Barger C, Basu S, et al. PTEN, RASSF1 and DAPK site-specific hypermethylation and outcome in surgically treated stage I and II nonsmall cell lung cancer patients. Int J Cancer. 2010;126:1630-9.

29. Guo S, Tan L, Pu W, Wu J, Xu K, Wu J, et al. Quantitative assessment of the diagnostic role of APC promoter methylation in non-small cell lung cancer. Clin Epigenetics. 2014;6(1):5.

30. Pesek M, Kopeckova M, Benesova L, Meszarosova A, Mukensnabl P, Bruha F, et al. Clinical significance of hypermethylation status in NSCLC: evaluation of a 30-gene panel in patients with advanced disease. Anticancer Res. 2011:31:4647-52

31. Hawes SE, Stern JE, Feng Q, Wiens LW, Rasey JS, Lu H, et al. DNA hypermethylation of tumors from non-small cell lung cancer (NSCLC) patients is associated with genderand histologic type. Lung Cancer. 2010;69:172-9.

32. Gao L, Xie E, Yu T, Chen D, Zhang L, Zhang B, et al. Methylated APC and RASSF1A in multiple specimens contribute to the differential diagnosis of patients with undetermined solitary pulmonary nodules. J Thorac Dis. 2015;7:422-32.

33. Pan SY, Xie EF, Shu YQ, Gao L, Zhang LX, Chen D, et al. Methylation quantification of adenomatous polyposis coli (APC) gene promoter in plasma of lung cancer patients. Ai Zheng. 2009;28:384-9.

34. Usadel H, Brabender J, Danenberg KD, Jeronimo C, Harden S, Engles J, et al. Quantitative adenomatous polyposis coli promoter methylation analysis in tumor tissue, serum, and plasma DNA of patients with lung cancer. Cancer Res. 2002;62:371-5.

35. Rykova EY, Skvortsova TE, Laktionov PP, Tamkovich SN, Bryzgunova OE, Starikov AV, et al. Investigation of tumor-derived extracellular DNA in blood of cancer patients by methylation-specific PCR. Nucleosides Nucleotides Nucleic Acids. 2004;23:855-9.

36. Begum S, Brait M, Dasqupta S, Ostrow KL, Zahurak M, Carvalho AL, et al. An epigenetic marker panel for detection of lung cancer using cell-free serum DNA. Clin Cancer Res. 2011;17:4494-503.

37. Zhang $Y$, Wang $R$, Song $H$, Huang G, Yi J, Zheng Y, et al. Methylation of multiple genes as a candidate biomarker in non-small cell lung cancer. Cancer Lett. 2011;303:21-8.

38. Therasse P, Arbuck SG, Eisenhauer EA, Wanders J, Kaplan RS, Rubinstein L, et al. New guidelines to evaluate the response to treatment in solid tumors. European Organization for Research and Treatment of Cancer, National Cancer Institute of the United States, National Cancer Institute of Canada. J Natl Cancer Inst. 2000;92:205-16.

39. Pan S, Xia W, Ding Q, Shu Y, Xu T, Geng Y, et al. Can plasma DNA monitoring be employed in personalized chemotherapy for patients with advanced lung cancer ? Biomed Pharmacother. 2012;66:131-7.

40. Herman JG, Graff JR, Myöhänen S, Nelkin BD, Baylin SB. Methylation-specific PCR: a novel PCR assay for methylation status of CPG islands. Proc Nat Acad Sci. 1996;93:9821-6.

\section{Submit your next manuscript to BioMed Central and take full advantage of:}

- Convenient online submission

- Thorough peer review

- No space constraints or color figure charges

- Immediate publication on acceptance

- Inclusion in PubMed, CAS, Scopus and Google Scholar

- Research which is freely available for redistribution 